\title{
FIRMS' REALIZATION ON THE INTENDED BENEFITS OF ADOPTION OF FOOD QUALITY METASYSTEMS: CASE OF ADOPTION OF HACCP IN THE AGRI-FOOD PROCESSING SECTOR IN SRI LANKA
}

\author{
U. K. Jayasinghe-Mudalige', S. M. M. Ikram², \\ J. M. M. Udugama ${ }^{1}$, J. C. Edirisinghe ${ }^{1}$ and H. M. T. K. Herath ${ }^{1}$
}

\begin{abstract}
This study investigates extent to which the HACCP certified agri-food processing firms in Sri Lanka have "realized" (i.e. post-adoption experience) those "intended" (i.e. pre-adoption expectations) benefits upon having a food safety and quality metasystem in place. First, a series of in-depth interviews were undertaken with Quality Assurance/General Managers $(n=15)$ of HACCP certified firms, University Academics specialized on this discipline $(n=12)$ and Quality Management System Auditors/Executives ( $n=5)$ from the SLSI. The interviews were voice-recorded, transcribed, and analyzed though $N$-Vivo (version 7.0) qualitative data analysis software, which led to the categorization of firm's level of expectation (E) and subsequent realization $(R)$ with regard to 14 different incentives that can be attributed to four major types of economic incentives that motivate a firm to act on food quality management, including: (1) External market-based, (2) Internal market-based; (3) Increased efficiency, and (4) Regulatory. Next, these 14 incentives were incorporated into a structured questionnaire in the form of attitudinal statements on which the respondents $(n=57)$ were asked to score on a two-way, four-point likert-scale to elicit their expectations and realizations. The ExpectationRealization diagram generated could differentiate those incentives on three criteria, i.e. $R>E$, $R=E$ and $R<E$. The results show that the most realized incentives (i.e. $R \geq E$ ) include external market-based incentives such as reduced customer complaints followed by improved internal efficiency. Further, it highlights that dairy, meat and fish processing firms realized more of those benefits than fruit/vegetable firms. The outcome of analysis provides insights for policy makers to recognize the importance of market-based incentives and the close interplay and interactions of which with regulatory incentives so as to develop a properly functioning incentive-based institutional set up for food safety.
\end{abstract}

Keywords: Agri-food processing sector in Sri Lanka, Economic incentives, Intended benefits, HACCP, Expectation - Realization diagram

\section{INTRODUCTION}

Parallel to the reforms of food safety regulation, both locally and globally, private enterprises are themselves implementing new forms of food safety controls in response to the demands of the market and/or internal economic and management pressures. These

firms are adopting different forms of food quality and safety metasystems, including the HACCP (Hazard Analysis \& Critical Control Points) and ISO 22000. The decision on adoption of food safety controls by firms will depend on perceptions of internal costs

\footnotetext{
1 Dept. of Agribusiness Management,Faculty of Agriculture \& Plantation Management, Wayamba University of 12 Sri Lanka,Makandura, Gonawila (NWP), 60170, Sri Lanka.

2 Nielsen Lanka Company (Pvt.) Ltd, Colombo 08.
} 
and benefits of adoption versus non-adoption (Caswell et al., 1998), as well as the potential for improvements in industrial performance, for example market share, profitability etc. (Rugman and Verbeke, 1998).

In turn, this will reflect, for example, the characteristics of the firm, its objectives, the type of product it manufactures, and the environment in which it operates. According to Henson and Caswell (1999), private enterprises can adopt a range of alternative food safety controls, either individually or in combination, that differ in their efficiency and effectiveness. Prior to adoption of such enhanced food safety metasystems, firms are guided by number of intended benefits, which the decisionmakers within the firms believe, will be obtained as an outcome of adoption. Firms vehemently target enhancement in operational performance as well as strategic growth within the sector through the implementation of a food safety control system. During the postimplementation period firms evaluate whether the intended benefits of adoption have been realized or whether unexpected costs have risen in comparison. This evaluation and subsequent judgments are critical factors that will influence firm decisions on whether to continue with the certification into the future and also decision that might arise on upcoming or novel quality assurance systems in the long term.

Antle (2000) and Antle (1995) emphasizes that government should intervene in food markets if it could generate "larger benefits" compared to those carried out by the market itself. However, it is unclear from this analysis "how large" and "who could decide" on the benefits from government intervention over those of the market to provide an appropriate level of food safety. In fact, this highlights the importance of an empirical study that looks into the problem of "what the firms received by adopting food safety controls?" and "would it beyond the expected value at the time of implementation?"

Herath et al. (2007), in the context of Canadian food processing sector, explores the association between the adoption of food safety and quality assurance practices and firm characteristics. It shows that the adoption of food safety and quality practices varies widely between individual firms according to, among others, firm size, country of ownership and control, level of innovativeness, level of export orientation, forms of food safety inspection, and the subsector in which the firm operates. Incentives of being able to access foreign markets play an important role in influencing HACCP adoption.

Jin and Zhou (2011), using the data from 124 Chinese agricultural cooperatives, found that size of the cooperative, perception and attitude of management toward standards, reputation, expected cost and benefit and the destination market have a positive and statistically significant relationship with the decision of the cooperatives to adopt the standards; however, it was unable to confirm the positive and significant effects of other factors such as innovativeness, price premium, customer attraction, and availability of support. Above findings suggest that the motivation for food businesses to implement public and private controls reflect prior expectations of the costs and benefits involved with each approach. In cases where businesses perceive the "costs" of implementation of these controls to be high relative to the "expected benefits", and when the difficulties posed on them cannot be avoided easily, there may be less motivation to implement enhanced food safety controls.

In the context of Sri Lankan fruit processing sector, Rajapakshe and Jayasinghe-Mudalige (2005) assesses the impact of a number of characteristics pertaining to a fruit processing firms to adopt the Sri Lankan Standards (SLS). It hypothesized that in the presence 
of a "mandatory" government regulation to adopt the SLS in the firm, the decision of the management to "invest" on it without removing any of their major products in the product mix or to exercise a "product exit" (i.e. removing a major product) will depend on factors such as the type of ownership, recent modifications made to the facility by introducing modern processing technologies, other enhanced food safety controls in place, whether the firm is involved with international markets, availability of skilled labor, and annual returns of the firm (adjusted to the number of employs and major products).

Many agri-food processing firms in Sri Lanka, driven by market forces and anticipated policy changes in different subsectors, have already taken initiatives to respond to these issues, and thus, have achieved certifications from various suppliers of standards. This again complicates the national need for food safety controls to be effective and cost efficient. If these firms are unsatisfied with the outcomes received from food safety system adoption, they might be motivated to discontinue implementation of controls. Understanding this dynamics of adoption is essential to maximize the safety of food products in an effective and efficient manner. This study would aid in the understanding of the dynamics of benefit-cost relationships in adopting an enhanced food safety metasystems by the firms operate in this sector, thus, contributing to the development of this sector as an engine for economic development.

The specific objectives of this study are, therefore, to identify the intended benefits of adopting a food safety metasystem by a firm operating in the agri-food processing sector in Sri Lanka, and to assess the extent to which the firms have realized the expected benefits identified. In doing so, it evaluate the perspectives of agri-food processing firms on the existing institutional policy framework for food quality assurance in terms of achieving the certification, and investigates the interplay between the firms' realization of intended benefits and its characteristics (i.e. firm type, size and the customer-base).

\section{METHODOLOGY}

\section{Development of Conceptual Framework}

The principal proposition put forward by this study is that a given agri-food processing firm may consider the adoption of an enhanced food safety metasystems as a project having implications with the administrative, technical, social and financial spheres of the enterprise. Addressing this issue with elements from project management literature, it can be stated that for a firm, the adoption of a food control system is a process, with the investment of resources being the inputs, and the achievement of food safety certification as the output.

For the firm, the "increased benefits" (e.g. enhanced reputation, market growth, and increase in revenue) and/or "decreased costs" (e.g. reduced product recalls, reduced liability costs) that result from adoption can be defined as outcomes of the project. Consider this firm at two points in time, P1 and P2 (with P2 occurring after time t) (Figure 01).

The firm does not have a food control system in place at P1 (pre-adoption), that is, it is without a food control system (WO). Two scenarios are possible at $\mathrm{P} 2$ :

1. The firm has adopted a food control system - with food control system (WI)

2. The firm has not adopted a food control system (WO) 


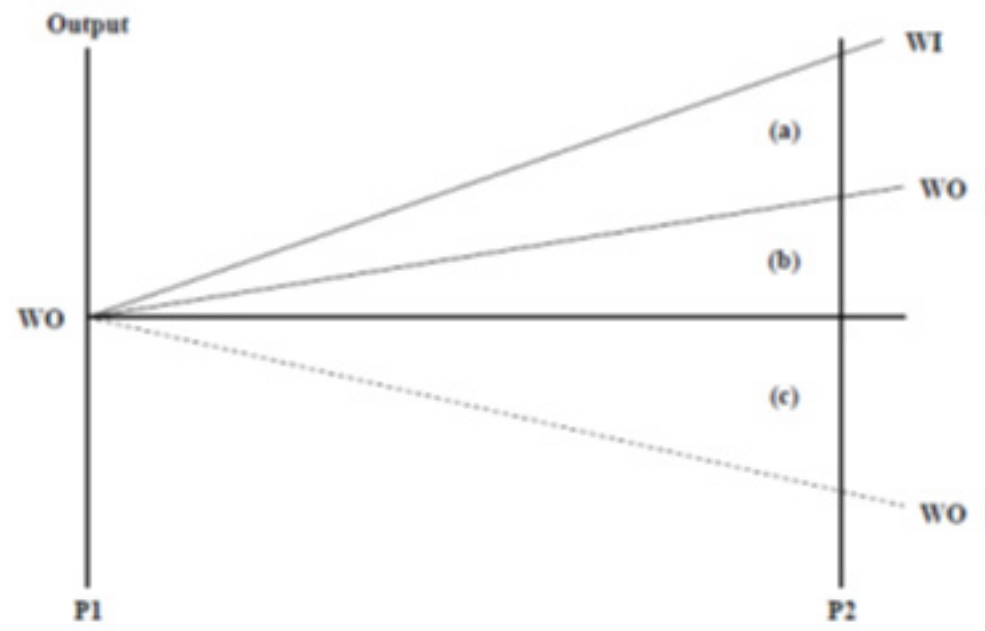

\section{Figure 01: Conceptualization of Incremental Net Benefit of adoption of a food safety metasystem}

At P2, with condition WO, the firm could continue with the same level of output, or it could have gained benefits (given as b), or it could have incurred losses (given as c). With condition WI, a firm could have gained benefits from the baseline level (inferred as $a+b$ ), or it could have gained benefits while overcoming the potential costs that have been prevented by adoption (inferred as a + $b+c)$. The Incremental Net Benefit obtained by adopting an enhanced food safety control system is (a). This study will assess what level of benefits firms had expected when adopting an enhanced food safety metasystems and to what extent these intended benefits were realized.

A Perception-Expectation framework (PE) is proposed here (Kenneth, 1993). A decision-maker within a firm has preadoption expectations of benefits (EB) when implementing a food control system and perceived benefits (PB) based on post-adoption experience (Spathis and Ananiadis, 2005). The level of satisfaction with a given food control system will depend on the relationship between the expected and perceived benefits:

1. $\mathrm{PB}-\mathrm{EB}=(+)$ Satisfied

2. $\mathrm{PB}-\mathrm{EB}=(0)$ Neutral

3. $\mathrm{PB}-\mathrm{EB}=(-)$ Dissatisfied
It can be argued that the INB realized by a firm (given as a), and perceived by the firm's management (EB) is the principal determinant on the continued implementation of a food safety system within that firm, and thus the above research proposition is of utmost importance to be studied.

\section{Area of Study and Data}

The sampling framework to collect data consists of a cross section of agri-food processing firms that have adopted an enhanced food safety metasystem, including the HACCP and ISO 22000 at least a year ago. Firms, in general, represent six subsectors in the agrifood processing sector in Sri Lanka, namely, (1) processed fruits and vegetables; (2) dairy products; (3) plantation products; (4) meat/ fish processing; (5) diversified processors, and (6) other processed products. The list was obtained from the Sri Lanka Standard Institutions, which comprises of more than 75 HACCP adopted firms.

Two-stage program of research was employed. Initially, an in-depth review of published theoretical and empirical literature in this area from developed and developing country contexts was carried out to identify factors related to benefits, costs, motives, constraints, 
and impacts of adopting enhanced food safety controls.

In order to identify these intended benefits of adopting a food safety metasystem, an exploratory qualitative grounded theory approach was adopted. Three sets of respondents were selected for assessment, including: (1) Managers (quality assurancel general managers) from fifteen large-scale agri-food processing firms (HACCP/ISO 22000 adopted at least two years ago, and having implemented more than one quality management system); (2) twelve academics from national universities (specialized in the areas of food technology, food marketing, and food quality assurance); and (3) five quality management system auditors/executives from the Sri Lanka Standards Institution.

Focus Group Discussions (supported by a Discussion Guide) and face-to-face indepth interviews (supported by a Structured Interview Schedule) were carried out with the above resource persons to extract their views, perceptions and ideas on this matter and also to expand and scrutinize on the factors extracted from literature. The interview and discussion session were voice recorded and transcribed. The data collected from the exploratory and review sessions were analyzed though $\mathrm{N}-$ Vivo (version 7.0) qualitative data analysis software. This helped to isolate cognitive and behavioral factors that are pertain to benefits, costs, constraints, and promoters for adoption of enhanced food safety metasystems.

The outcome of this process was used to develop a structured questionnaire to be used with the target group, which comprised of several parts to collect personal details of respondents, details about the firm and its quality systems and processes etc. More importantly, the questionnaire includes a number of benefits of HACCP/ISO22000 certification that have been identified by reviewing of literature and through the focus group discussions (see section: Results and Discussion below for 14 different aspects identified).

The questionnaire was pretested with a crosssection of the proposed sample $(n=5)$ and modifications were made to the final version as per the outcomes of the validation exercise. A face-to-face interview with the manager responsible for food safety and quality assurance/owner of the firm were carried out $(n=57)$ between March and September 2012 with the support of the validated structured questionnaire to collect data followed by a site inspection and a search for records to verify the status of adoption of HACCP.

\section{Development of "Perception - Expectation Matrix"}

The 16 potential responses obtained through scores provided to the two-way four-point likert scale for 14 different aspects expressing the importance of adoption of food safety controls like HACCP / ISO 22000 (Table 01) was utilized to develop the Perception - Expectation Matrix. Accordingly, we can illustrate the 16 possible answers for each aspect as follows (Figure 02).

The 'circles' in the main diagonal of the matrix represent the responses where that is given to the Expectation is tally with the Realization, i.e. $\mathrm{E}=\mathrm{R}$. All the 'triangles' symbolize that Realization is greater than the Expectation $(E<R)$. The color variation shows the intensity of Expectation and Realization such as E1R3 and E2R4 has equal gaps between Expectation and Realization (2), where E1R2, E2R3, and E3R4 have equal gaps (1). The 'squares' represent the responses where Expectation is greater than the Realization $(\mathrm{E}>\mathrm{R})$. 
Table 01: Potential Responses on the Two-Way Four-Point Likert Scale

\begin{tabular}{cccc}
\hline & Expectation & & Realization \\
\hline Symbol & Level & Symbol & Level \\
\hline E1 & Not At All Expected & R1 & Not Realized \\
E2 & Not Much Expected & R2 & Poorly Realized \\
E3 & Somewhat Expected & R3 & Somewhat Realized \\
E4 & Strongly Expected & R4 & Completely Realized \\
\hline
\end{tabular}

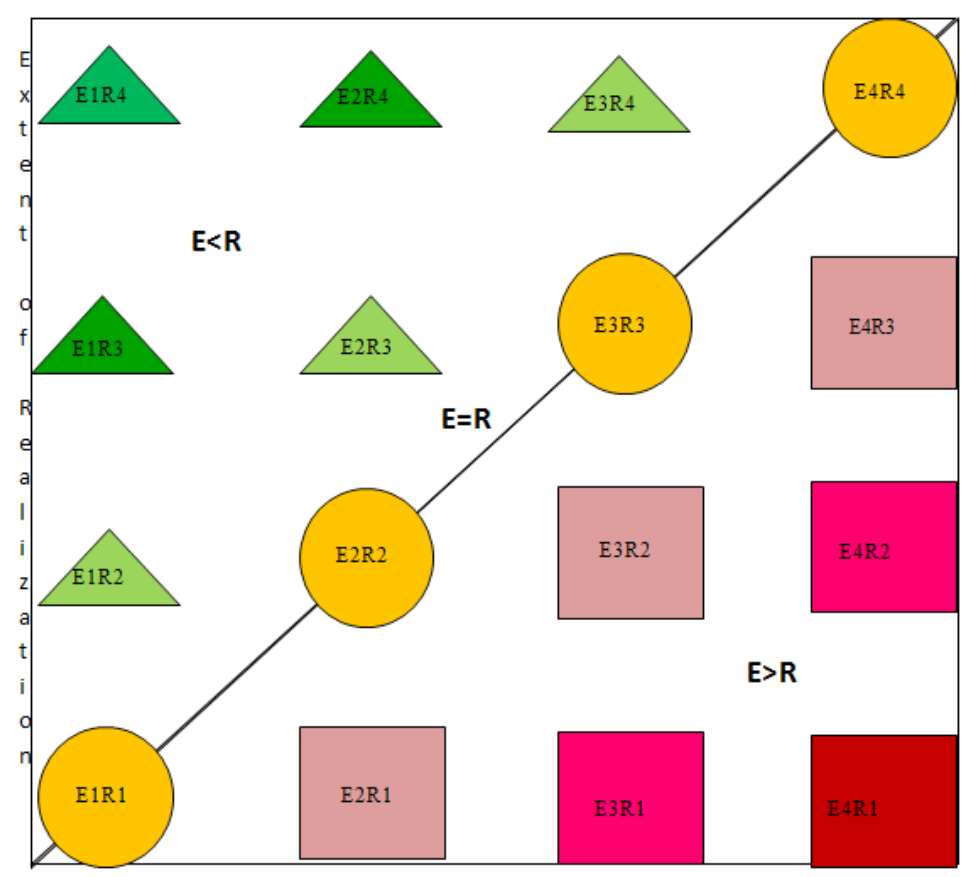

Extent of Expectation

Figure 02: Perception - Expectation Matrix

\section{RESULTS AND DISCUSSION}

\section{Identifying Potential/Intended Benefits to the Firm}

Utilizing the coding-retrieval and node development functionalities in N-Vivo, it was possible to develop a qualitative model to link the different cognitive parameters unearthed from the interviews and discussions and relate and/or interpret them in terms of concepts from existing literature (Figure 03).

The most common benefits expected were increase in sales and market share, engaging in international marketing, and improvement in the image of the company. The ability to charge a higher price for their products and meeting the industry benchmark were also strongly expected benefits of certification. Food processors further expect a reduction in product related problems and customer complaints. Some interesting expectations of companies from food safety management system adoption were improvement in productivity, meeting regulatory requirements and reducing the interference of various pressure groups. It was not altogether surprising that firms have associated HACCP/ ISO 22000 implementation with profitability and customer satisfaction. However these 
companies have also equated certification with corporate responsibility, competitive advantage and organizational innovation.

These elements of incentives identified through this process can broadly be classified into 9 individual incentives under three main types of economic incentives, including: market-based incentives such as (1) financial implications/ cost (CST); (2) efficiency in human resources (HRE); (3) efficiency in technical procedures (TCE); (4) sales and revenue (SLR); (5) reputation (REP), and (6) commercial pressure (CPR); regulatory incentives such as (7) existing government regulation (EGR) and (8) anticipated government regulation (AGR), and Liability incentives such as (9) liability laws (LBL). However, we have resolved to further integrate these nine incentives into four broad types of incentives, including: (1) Marketbased incentives - external; (2) Market-based incentives - Internal; (3) Technical efficiency of the firm, and (4) Regulatory requirements. Next, to get the views of respondents on each incentive on different facets associated with it, we have come up with the 14 potential outcomes resulting from adoption of HACCP / ISO 22000 shown in Table 02.

\section{Descriptive Statistics of the Sample Participated to Questionnaire-based Survey}

Out of the firms participated to the study ( $\mathrm{n}$ $=57)$, the majority of firms $(69 \%)$ have been in business for over 10 years, and about $60 \%$ of firms is categorized as large firms, since they possess over 100 employees. Nearly 53\% firms earns over Rs. 100 million per annum, while $16 \%$ of firm's turnover falls under the category of Rs. 50 - 100 million per annum. With respect to the firm type, nearly $48 \%$ of firms involve with meat and/or fish product processing, while 27 and 6 percent involved with beverage and dairy products, respectively. Most of the firms (74\%) engaged in export market, while the rest only served local market.

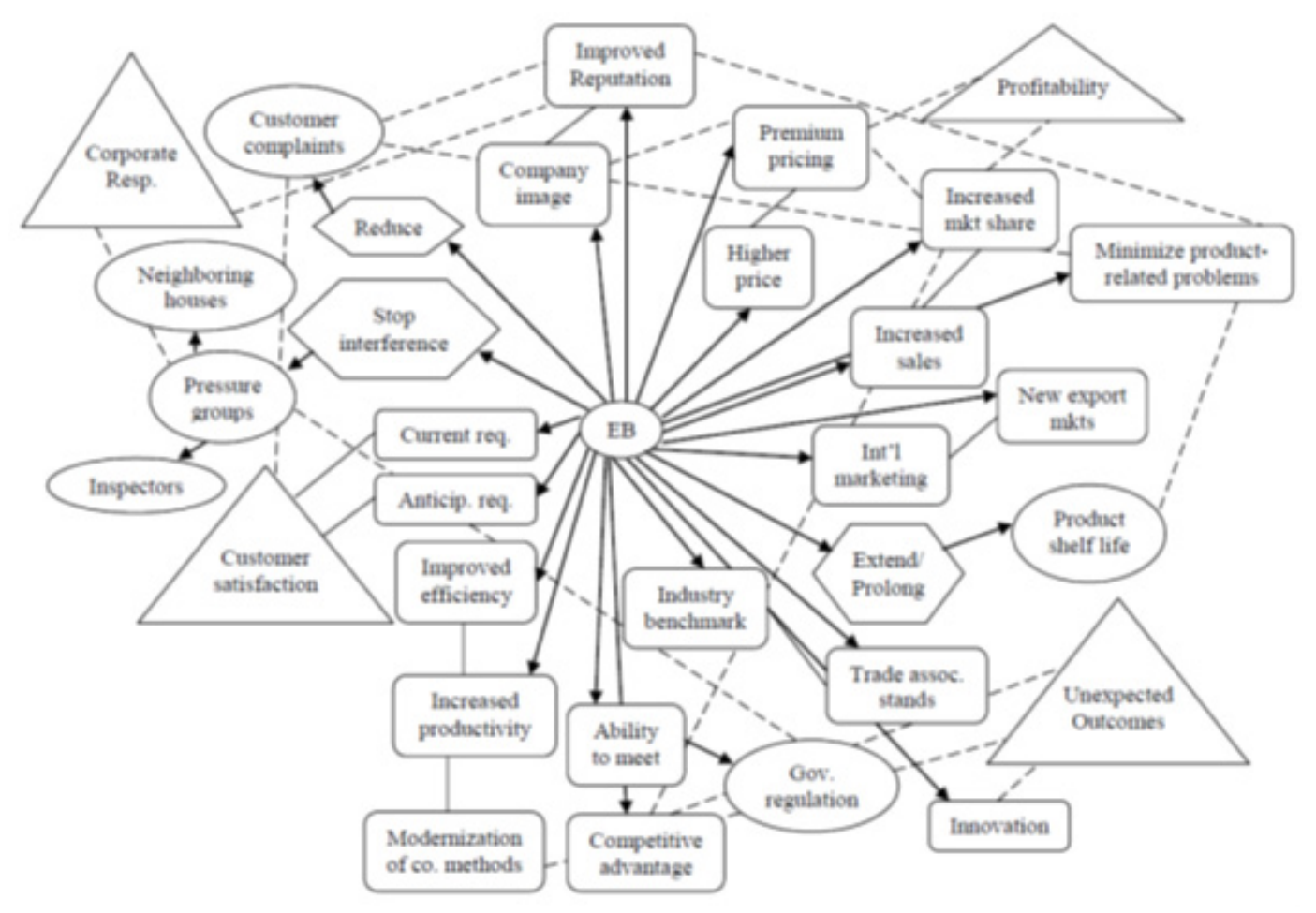

Figure 03: Qualitative model illustrating the intended benefits 
Table 02: Incentives and intended benefits identified

\begin{tabular}{cl}
\hline No & \multicolumn{1}{c}{ Incentive / Intended benefit } \\
\hline 1 & Market-Based Incentives - External \\
1.1 & Improvement in company image/reputation \\
1.2 & Reduced interference of stakeholders/pressure groups \\
1.3 & Ability to meet anticipated customer requirements \\
1.4 & Reduction in customer complaints \\
1.5 & Satisfaction of current customer requirements \\
2 & Market-Based Incentives - Internal \\
2.1 & Increase sales/market share in existing markets \\
2.2 & Obtain higher price for products \\
2.3 & Access to new international/export markets \\
2.4 & Differentiation/repositioning of products in market \\
3 & Internal Efficiency \\
3.1 & Minimizing the occurrence of product related problems \\
3.2 & Improved efficiency/productivity of the firm \\
3.3 & Prolonged shelf life of products \\
3.4 & Meeting industry/trade association standards \\
4 & Government Regulatory Requirements \\
4.1 & Improved ability to meet government regulatory requirements \\
\hline
\end{tabular}

Almost $96 \%$ of firms did not wish to adopt another quality system except HACCP while others indicated their willingness to be certified for others systems like ISO 9001 and ISO 14000. It is evident that nearly $70 \%$ of firms marketed their products only under their own brand, while others involve with marketing their products only under a customer brand or in bulk to wholesalers, respectively.

\section{Exploring the Gaps between Expectations and Realizations}

Table 03 shows the percentages obtained by each of the 16 responses possible on the twoway four-point likert-scales set for the 14 intended benefits on their level of expectation $\left(\mathrm{E}_{1}, \mathrm{E}_{2}, \mathrm{E}_{3}\right.$ and $\left.\mathrm{E}_{4}\right)$ and realization $\left(\mathrm{R}_{1}, \mathrm{R}_{2}, \mathrm{R}_{3}\right.$ and $\mathrm{R}_{4}$ ) (Table 01).

Figure 03 show that $E_{3} R_{3}, E_{4} R_{3}$ and $E_{4} R_{4}$ possess the highest percentages out of 16 responses. This suggests that a vast majority of firms highlight that they could achieve (i.e. realization) the level what they wanted to have (i.e. expectation) positively. With regard to the external market-based incentives, the outcome of analysis shows that about 67.4 percent of firms have realized what they expect with respect to ability of HACCP/ ISO22000 certification to improve the image of the company and to reduce interference of various stakeholders and pressure groups. However, almost 72 and 91 percent of firms, respectively, have indicated that they realized what they expect with respect to ability of HACCP/ISO22000 certification to satisfy the requirements of anticipated customers of the firm, and capability of firm to reduce customer complaints with the metasystem in place. Further, about 70 percent of firms expressed that certification to which satisfies requirements of the current customer base of the firm. 
Table 03: Percentage obtained by 16 responses for 14 intended benefits

\begin{tabular}{|c|c|c|c|c|c|c|c|c|c|c|c|c|c|c|}
\hline & \multicolumn{5}{|c|}{ Market Based } & \multicolumn{4}{|c|}{ Markey Based } & \multicolumn{4}{|c|}{ Internal } & \multirow[t]{2}{*}{ Regulatory } \\
\hline & \multicolumn{5}{|c|}{ External } & \multicolumn{4}{|c|}{ Internal } & \multicolumn{4}{|c|}{ Efficiency } & \\
\hline & 1.1 & 1.2 & 1.3 & 1.4 & 1.5 & 2.1 & 2.2 & 2.3 & 2.4 & 3.1 & 3.2 & 3.3 & 3.4 & 4.1 \\
\hline $\mathrm{E}_{1} \mathrm{R}_{1}$ & 2.8 & 6.5 & - & - & - & - & 2.8 & 2.8 & 2.8 & - & - & 2.8 & - & - \\
\hline $\mathrm{E}_{1} \mathrm{R}_{2}$ & - & 2.8 & - & - & 2.17 & - & - & - & - & - & - & - & - & 2.8 \\
\hline $\mathrm{E}_{1} \mathrm{R}_{3}$ & - & - & - & - & 2.17 & - & - & - & 2.8 & - & - & -- & - & - \\
\hline $\mathrm{E}_{1} \mathrm{R}_{4}$ & - & 2.8 & - & - & - & - & 2.8 & - & 2.8 & - & - & 2.8 & - & - \\
\hline $\mathrm{E}_{2} \mathrm{R}_{1}$ & - & 2.8 & 2.8 & - & - & - & - & 4.4 & 2.8 & - & - & - & 2.8 & - \\
\hline $\mathrm{E}_{2} \mathrm{R}_{2}$ & - & 4.4 & 2.8 & - & - & - & - & 2.8 & 4.4 & 4.4 & 2.8 & - & 2.8 & - \\
\hline $\mathrm{E}_{2} \mathrm{R}_{3}$ & - & 4.4 & - & 6.5 & - & 2.8 & 11.0 & - & 4.4 & 4.4 & 2.8 & 11.0 & - & 4.4 \\
\hline $\mathrm{E}_{2} \mathrm{R}_{4}$ & - & 6.5 & - & 2.8 & - & - & 2.8 & - & - & - & - & 2.8 & - & - \\
\hline $\mathrm{E}_{3} \mathrm{R}_{1}$ & - & - & 2.8 & - & - & 2.8 & - & 4.4 & 2.8 & - & - & - & 2.8 & - \\
\hline $\mathrm{E}_{3} \mathrm{R}_{2}$ & 4.4 & 4.4 & 2.8 & - & - & 2.8 & - & 2.8 & 8.7 & 4.4 & - & - & 2.8 & - \\
\hline $\mathrm{E}_{3} \mathrm{R}_{3}$ & 6.5 & 28.3 & - & 8.7 & 23.9 & 19.6 & 34.8 & 15.2 & 37.0 & 23.9 & 32.6 & 34.9 & 28.3 & 8.7 \\
\hline $\mathrm{E}_{3} \mathrm{R}_{4}$ & 2.8 & 2.8 & - & - & 6.52 & - & 4.4 & 4.4 & 4.8 & 2.8 & 2.8 & 4.4 & 2.8 & 10.9 \\
\hline $\mathrm{E}_{4} \mathrm{R}_{1}$ & 4.4 & 2.8 & 2.8 & - & 4.35 & 4 & 2.8 & - & - & 2.8 & - & 2.8 & 4.4 & 10.9 \\
\hline $\mathrm{E}_{4} \mathrm{R}_{2}$ & 6.5 & 2.1 & - & 2.8 & 2.17 & 4.4 & 2.8 & 4.4 & 2.17 & 4.4 & 6.5 & 2.8 & 2.16 & - \\
\hline $\mathrm{E}_{4} \mathrm{R}_{3}$ & 17.4 & 21.9 & 17.4 & 45.7 & 23.9 & 34.8 & 13.0 & 28.3 & 13.0 & 28.3 & 23.9 & 13.0 & 19.6 & 23.9 \\
\hline $\mathrm{E}_{4} \mathrm{R}_{4}$ & 55.2 & 10.9 & 30.4 & 34.8 & 34.8 & 34.8 & 13.0 & 32.6 & 15.2 & 26.1 & 30.4 & 13.0 & 34.9 & 39.1 \\
\hline $\mathrm{E} \leq \mathrm{R}$ & 67.4 & 67.4 & 71.7 & 91.3 & 69.6 & 56.5 & 63.0 & 56.5 & 71.7 & 60.9 & 69.6 & 80.4 & 67.4 & 65.2 \\
\hline$E>R$ & 32.6 & 32.6 & 28.3 & 8.7 & 30.1 & 43.5 & 37.0 & 43.5 & 28.3 & 39.1 & 30.4 & 19.6 & 32.6 & 34.8 \\
\hline
\end{tabular}

Note: Refer Table 2 for description of notations 1.1 to 4.1.

With respect to the internal market-based incentives, it shows that nearly 57 percent of firms have realized what they expect with respect to increase in sales by adopting HACCP/ISO22000 certification and its ability to gain an access to new international / export markets. The percentage is slightly high, i.e. $60 \%$, with respect to capability of the certification to generate a higher price for their products, and $72 \%$ for firm's increased ability to differentiate and reposition of its major products in the market.

The percentages are slightly varied with respect to the four intended benefits listed under the internal efficiency criteria. For example, only 61 percent of firms have realized what they expect with respect to ability of HACCP/ISO22000 certification to minimize the occurrences of product related issues in the firm, while this is 67 percent for its ability to reduce interference of various stakeholders and pressure groups. Almost 70 percent of firms have indicted it could improve their internal efficiency and productivity of the firm, while 80 percent of firms have realized that it generates a prolong shelf life for their products. Moreover, the results suggests that nearly two third of firms have realized what they expect with regard to ability of $\mathrm{HACCP} /$ ISO22000 certification to meet the government regulatory requirements in effect.

It was of interest to examine the percentage of firms in the sample showing the characteristic of $(E \leq R)$, i.e. those firms who realized, ex-post, the given criterion beyond the expectations, ex-ante, or $(E>R)$, those firms who did not realize, ex-post, the same criterion beyond the expectations, ex-ante, about it. Figure 04 illustrates the outcome of analysis. We can infer that the majority 
of firms $(>50 \%)$ have realized the criterion explained in each statement the outcomes beyond its expectations, i.e. $(\mathrm{E} \leq \mathrm{R})>(\mathrm{E}>\mathrm{R})]$. However, there exists a considerable variation with respect to intended benefits categorized under each category, i.e. internal and external market-based incentives, technical efficiency, and regulation etc.

\section{CONCLUSIONS}

The specific objective of this study was to investigate, based on the Expectation - Disconfirmation theory from consumer behavior literature, extent to which those HACCP certified agri-food processing firms in Sri Lanka have "realized" (i.e. firm' postadoption experience) those "intended" (i.e. pre-adoption expectations) benefits upon having a food safety and quality metasystem in place.
The outcome of this process led to the categorization of firm's level of expectation (E) and subsequent realization (R) with regard to 14 different incentives, which can be attributed to four major types of economic incentives that motivate a firm to act on food quality management. The outcome of analysis show that the most realized incentives (i.e. $\mathrm{R} \geq \mathrm{E}$ ), i.e. the gap between realization and expectations was largest, include those classified under the external market-based incentives (i.e. ability to better deal with external market forces/incentives such as company image and customer complaints) followed by improved internal efficiency in comparison to those internal market-based incentives such as charging a premium for their products, increased sales/revenue and dealing with regulatory pressure.

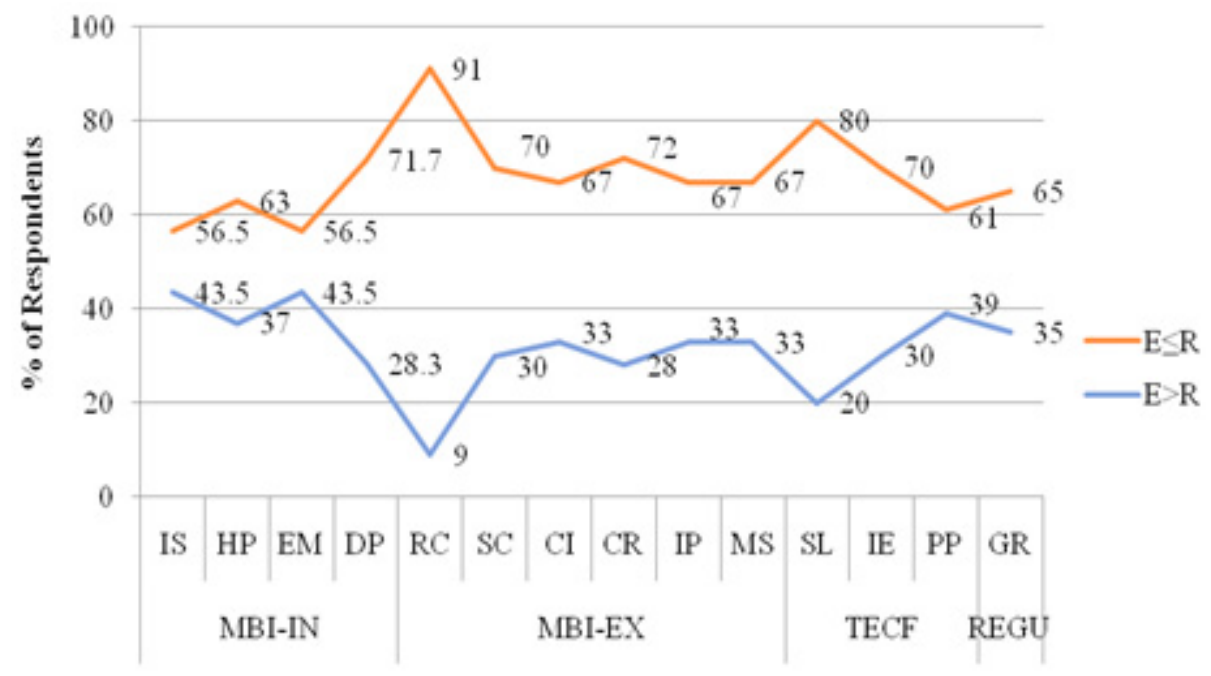

Outcomes

\section{Figure 04: Variation of percentage of firm showing $E \leq R)$ and $(E>R)$ in the sample}

Note: IS = Increased Sales; HP = Obtain Higher Price; EM= Access to Export Markets; DP = Differentiation of Products; RC = Reduction in Customer Complaints; $\mathrm{SC}=$ Satisfaction of Customer Requirements; CI = Improvement in Reputation; $\mathrm{CR}=$ Meet Anticipated Customer Requirements; IP = Interference of Pressure Groups; MS = Meeting Industry standards; SL = Shelf life of Products; IE = Improved Efficiency of the Firm; PP = Minimizing Product Related Problems; GR = Meet Regulatory Requirements 
Further, the results highlight that those dairy, meat/fish processing firms realized more of those benefits than fruit/vegetable firms while firm size and turnover also had variable impacts. Overall, the outcome of analysis imply that those certified firms are "happy" with the multi-faceted incentives generated by the metasystem ex-post over the investments made on it (i.e. financial, human and physical resources) ex-ante. This creates the need for policy makers to recognize the importance of market-based incentives and the close interplay and interactions of which with regulatory incentives, and in turn, importance of development of a properly functioning regulatory and liability system and a steadfast system to inject market-based motivators such as brand equity to promote adoption of HACCP among firms.

\section{ACKNOWLEDGEMENTS}

We acknowledge the financial assistance provided by the National Science Foundation of Sri Lanka under its competitive grant scheme (NSF/RG/2011/AG/01) to carry out this study. The support extended by Mr. T. G. G. Dharmawardana (Director - Systems Certification Division of the SLSI), Ms. Buddhika Goroggoda (Rajarata University of Sri Lanka) and Ms. Lakmini Wasana (Wayamba University of Sri Lanka) and the owners/managers of firms participated to the study are also much appreciated.

\section{REFERENCES}

Antle, J. M. (2000). No such thing as a free safe lunch: the cost of food safety regulation in the meat industry. American Journal of Agricultural Economics, 82 (May): 310-322.

Antle, J. M. (1999). Benefits and costs of food safety regulation. Food Policy, 24: 605-623.

Caswell, J. A., Bredahl, M. E., and Hooker, N. H. (1998). How quality management metasystems are affecting food industry. Review of Agricultural Economics, 20: 547-557.

Henson, S. and Caswell, J. (1999). Food safety regulation: an overview of contemporary issues. Food Policy, 24: 589-603.

Herath, D., Hassan, Z, Henson, S. (2007). Adoption of food safety and quality controls: do firm characteristics matter? Evidence from the Canadian food processing sector. Canadian Journal of Agricultural Economics, 55(3): 299-314.

Jin, S. and Zhou, J. (2011). Adoption of food safety and quality standards by China's agricultural cooperatives. Food Control, 22(2): 204-208.

Kenneth. (1993). Expectations, performance evaluation, and consumers' perceptions of quality. Journal of Marketing, 57(4): 18-34.

Rajapakse, S. and Jayasinghe-Mudalige, U. K. (2005), Fate of the product mix of a firm in a mandate to adopt a food quality metasystem: the case of adoption of the SLS in fruit processing sector in Sri Lanka, Sri Lankan Journal of Agricultural Economics, 7(1): 33 $-50$. 
Rugman, A. M., and Verbeke, A. (1998). Corporate strategy and international environmental policy. Journal of International Business Studies, 29(4): 819-834.

Spathis, C. and Ananiadis, J. 2005. Assessing the benefits of using an enterprise system in accounting information and management. The Journal of Enterprise Information Management, 18(2): 195-210. http://dx.doi.org/10.1108/17410390510579918 